\title{
Statistical Approach To Reduce Pollution Load From Paper Mill Effluent By Using Coagulation \& Adsorption Methods
}

\author{
Pooja Tripathi \\ Cellulose and Paper Division, Forest Research Institute, Dehradun, India
}

\begin{abstract}
There are 759 paper mills in India with an operating capacity of 12.7 million tonnes and consumption of 11 million tonnes with $9.3 \mathrm{~kg}$ per capita consumption of paper. The paper industry uses large quantity of freshwater for paper production and similarly generates large quantity of effluent. The generated effluent is characterized by $\mathrm{pH}$, dark color, pungent odour, suspended solids and high organic and inorganic load in terms of chemical oxygen demand (COD) and biochemical oxygen demand (BOD). Starting from such considerations, physico-chemical treatment was performed by using coagulation and adsorption to target color, $C O D, B O D$ and AOX with statistical approach. For optimization, fractional factorial design was used to develop experimental runs and STATISTICA 7 software was used for the data analysis. After chemical treatment, maximum $78.67 \%$ reduction was found in COD and $72.58 \%$ reduction in color, with $500 \mathrm{mgL}^{-1}$ dose of ferric chloride. After adsorption treatment, maximum $94.12 \%$ reduction was found in color and $73.85 \%$ reduction in COD with $550 \mathrm{mgL}^{-1}$ dose of activated charcoal. Based on results, it is revealed that the ferric chloride and activated charcoal both were found effective for reduction of pollution load from paper mill effluent at environmental regulatory parameters.
\end{abstract}

Keywords: Adsorption, coagulation, optimization, pulp and paper mill effluent, physico-chemical treatment

\section{Introduction}

Water is one of the basic essential requirement for human beings in daily life. However, with rapid development of modern industries water pollution turned more serious day by day, on the other hand the higher quantity of water demand with increasingly stringent environmental quality standards. Most of the industries such as textile, leather, paper and plastic industries pollute the water by direct discharge of industrial wastewater without proper treatment into the river, sea and land etc $[1,2]$.

Pulp and paper mill industry is one of the $17^{\text {th }}$ most polluting industries in India and it discharges a large volume of highly toxic and colored wastewater into the environment. Per day $330 \mathrm{~m}^{3}$ of wastewater is generated from per ton of paper produced. Nearly, $75-95 \%$ of fresh water, which is used in the pulp and paper mill is discharged as effluent. The effluent is characterized by dark color, foul odour, chemical oxygen demand (COD), biochemical oxygen demand (BOD) and $\mathrm{pH}[2,3,4]$. The dark color in paper mill effluent is caused due to the presence of organic ligands such as wood extractives, resins, synthetic dyes, tannins, lignin and its degradation products. The wastewater has to meet the national standards of discharge limits before disposal onto land or water bodies [5-9]. Several physico-chemical and biological treatment methods employing a variety of chemicals and microorganisms have been proposed in the past to remove COD, BOD and color from wastewater and the drawbacks of these methods have been reported [10,11].

The coagulation and adsorption of coloring matter and its removal from paper industry wastewaters using lime and salts of iron and aluminum are already reported in literature [4,9,7,11]. However, no systematic study related to removal of color, COD, BOD from wastewater by ferric chloride and activated charcoal is found in literature and the present study is an attempt in that direction. The major objective identified for this study is to assess the ability of $\mathrm{FeCl}_{3}$ and activated charcoal to precipitate and adsorb to reduce pollutants from paper industry wastewater with statistical approach.

\section{Materials and Methods}

2.1 Effluent and its characterization: In the present study the effluent samples were collected from the agro based paper mill and it was stored in the refrigerator at $4^{\circ} \mathrm{C}$ until their usage. The physico-chemical characteristics of effluent were determined by using American Public Health Association (APHA) and Canadian Pulp and Paper Association (CPPA) methods [12,13].

2.2 Statistical methodology: Fractional factorial design was used to get experimental runs for ferric chloride and activated charcoal treatment at different doses, $\mathrm{pH}$ and retention time. It has given 81 experimental runs for ferric choride and 27 experimental runs for activated charcoal treatment respectively. After treatment, results were analyzed with STSTISTICA 7 software to get an optimized treatment condition on which maximum pollution load reduction was found. 
2.3 Coagulation treatment: For the treatment of paper mill effluent with $\mathrm{FeCl}_{3}, 100 \mathrm{ml}$ of untreated effluent was taken in $300 \mathrm{ml}$ glass stoppered bottles containing predetermined doses of $\mathrm{FeCl}_{3}$. The content in the bottle was mixed thoroughly by repeated inversion and the $\mathrm{pH}$ was adjusted to the desired value. The bottles were then left unshaken to facilitate the formation and sedimentation of precipitates. After precipitation supernatant was taken for the analysis.

2.4 Adsorption treatment: The adsorption process was performed at ambient temperature in an orbital shaker cum incubator. During the test, $50 \mathrm{ml}$ of paper mill effluent was added into $100 \mathrm{ml}$ capacity of conical flask. In each flask, different doses of activated carbon were added. After adding adsorbant dose, $\mathrm{pH}$ of the wastewater was adjusted at 7 . The flasks were then shaked at $120 \mathrm{rpm}$ and kept for sedimentation at different retention time. The treated samples were then filtered by passing through a Whatman filter paper (pore size $1.2 \mu \mathrm{m}$ ) and the filtrate was analyzed for different parameters.

TABLE-1: Physico-chemical characterization of paper mill effluent

\begin{tabular}{|c|c|c|}
\hline Parameters measured & Unit & Parameters value \\
\hline $\mathrm{pH}$ & - & 9.14 \\
\hline Color & $\mathrm{PCU}$ & 3943.15 \\
\hline COD & $\mathrm{mgL}^{-1}$ & 2720 \\
\hline BOD & $\mathrm{mgL}^{-1}$ & 1349.33 \\
\hline TDS & $\mathrm{mgL}^{-1}$ & 2393.33 \\
\hline TSS & $\mathrm{mgL}^{-1}$ & 1175.33 \\
\hline Turbidity & $\mathrm{NTU}^{-1}$ & 484.33 \\
\hline AOX & $\mathrm{mgL}^{-1}$ & 13.76 \\
\hline
\end{tabular}

Each reading is the mean of three replications with $\pm \mathrm{SE}$

\section{Results and Discussion}

3.1 Effluent characteristics: The paper industry effluent characteristics were analyzed and the results of analysis are shown in Table-1. The effluent used in the study was dark brown in color and its pH was 9.15. This would be due to the addition of alkali for the precipitation of total solids. The alkali reacts with the water and produces higher no. of hydroxyl ions which raises the $\mathrm{pH}$ of effluent and makes it alkaline in nature [14]. The analysis showed the high presence of color (3943.15 PCU), which mainly arises due to the presence of low and high molecular weight chlorinated organic compound generated from the lignin degradation product which are produced during different stages like pulping, bleaching and alkali extraction $[14,11]$. The wastewater was also having high BOD (1349.33 mg/l) and COD (2720 mg/l) in wastewater, which could be due to the different raw materials and processing chemicals were used during pulping. Most of the estimated parameters in effluent exceed for the disposal of wastewater by Minimal National Standards.

3.2 Mechanism of coagulation: Maximum pollution reduction was found at $550 \mathrm{mgL}^{-1}$ dose of ferric chloride at $\mathrm{pH} 4,78.67 \%$ COD, $64.42 \%$ BOD, $72.58 \%$ color and $52.54 \%$ AOX were reduced as shown in Table-2. The coagulation was brought about by mixing a predetermined quantity of $\mathrm{FeCl}_{3}$ to $100 \mathrm{ml}$ wastewater at a particular $\mathrm{pH}$. The addition of $\mathrm{FeCl}_{3}$ initially produced dark brown floc, which eventually formed larger aggregates and settled down as sludge. The supernatant obtained upon centrifugation was clear and lighter in color. Accordingly, in aqueous medium, the trivalent metal cations hydrolyses to form positively charged monomeric and polymeric species that have a very large surface area and they tend to adsorb onto surface of negatively charged coloring organic matter and forms insoluble precipitates which eventually settle down as sludge [11]. The coagulation is dependant on dose. The use of high doses of metal salt improves the rate of precipitation by two mechanisms: (a) by increasing concentration of metal hydroxide and aggregation rate, and (b) by enmeshing organic ligands into large aggregates by sweep floc coagulation $[11,12]$.

TABLE-2: Effluent characteristics before and after treatment with $500 \mathrm{mgL}^{-1}$ dose of $\mathrm{FeCl}_{3}$ at $\mathrm{pH} 4,212.5 \mathrm{rpm}$ and 45 min retention time

\begin{tabular}{|c|c|c|c|}
\hline $\begin{array}{c}\text { Pollution } \\
\text { Parameter }\end{array}$ & Unit & $\begin{array}{c}\text { Before } \\
\text { Treatment }\end{array}$ & $\begin{array}{c}\text { After Treatment } \\
\text { (with \% reduction) }\end{array}$ \\
\hline Color & $\mathrm{PCU}$ & 3943.15 & $1081.17(72.58 \%)$ \\
\hline COD & $\mathrm{mgL}^{-1}$ & 2720 & $580.03(78.67 \%)$ \\
\hline BOD & $\mathrm{mgL}^{-1}$ & 1349.33 & $660.42(51.05 \%)$ \\
\hline TDS & $\mathrm{mgL}^{-1}$ & 2393.33 & $2121.66(11.35 \%)$ \\
\hline TSS & $\mathrm{mLL}^{-1}$ & 1175.33 & $849.00(27.60 \%)$ \\
\hline Turbidity & $\mathrm{NTU}^{-1}$ & 484.33 & $197.33(59.25 \%)$ \\
\hline AOX & $\mathrm{mgL}^{-1}$ & 13.76 & $6.53(52.54 \%)$ \\
\hline
\end{tabular}

Each reading is the mean of three replications with $\pm \mathrm{SE}$ 
3.3 Mechanism of adsorption: Maximum 94.12\% color, $73.85 \%$ COD, $64.42 \%$ COD and $58.01 \%$ turbidity were reduced with $550 \mathrm{mgL}^{-1}$ dose at $\mathrm{pH} 7$ of activated charcoal. Adsorption is usually explained in terms of surface tension (or energy per unit area) of the solid. Molecules in the interior of any solid are subjected to balanced forces, whereas surface molecules, are subjected to unbalanced forces toward the interior. The inward forces can only be satisfied if other molecules, usually liquid or gaseous, become attached on the surface of the solid. The forces of attraction, or Van der Wall's forces, are relatively weak and adsorption due to these forces is called physical adsorption because the absorbed species is easily removed from the adsorbent $[14,15]$.

TABLE-3: Effluent characteristics before and after treatment with $550 \mathrm{mgL}^{-1}$ activated charcoal at $\mathrm{pH} 7$

\begin{tabular}{|c|c|c|c|}
\hline $\begin{array}{c}\text { Pollution } \\
\text { Parameter }\end{array}$ & Unit & $\begin{array}{c}\text { Before } \\
\text { Treatment }\end{array}$ & $\begin{array}{c}\text { After Treatment } \\
\text { (with \% reduction) }\end{array}$ \\
\hline Color & PCU & 3943.15 & $231.48(94.12 \%)$ \\
\hline COD & $\mathrm{mgL}^{-1}$ & 2720 & $711.13(73.85 \%)$ \\
\hline BOD & $\mathrm{mgL}^{-1}$ & 1349.33 & $480.06(64.42 \%)$ \\
\hline TDS & $\mathrm{mgL}^{-1}$ & 2393.33 & $1916.66(19.91 \%)$ \\
\hline TSS & $\mathrm{mgL}^{-1}$ & 1175.33 & $969.33(17.52 \%)$ \\
\hline Turbidity & $\mathrm{NTU}^{-1}$ & 484.33 & $203.33(58.01 \%)$ \\
\hline AOX & $\mathrm{mgL}^{-1}$ & 13.76 & $8.26(39.97 \%)$ \\
\hline
\end{tabular}

Each reading is the mean of three replications with $\pm \mathrm{SE}$

3.4 Desirability surface curve: After performing all the experimental runs, data were analyzed by STATISTICA 7 software. It resulted an optimized condition with desirability value, at which maximum pollution load reduction was obtained after the treatment of effluent with ferric chloride and activated charcoal. At optimized condition, desirability surface curve was also found at desirability value, which showed the desirability between each two factors which were used to optimize the treatment condition for ferric chloride and activated charcoal both (Fig.1,2).

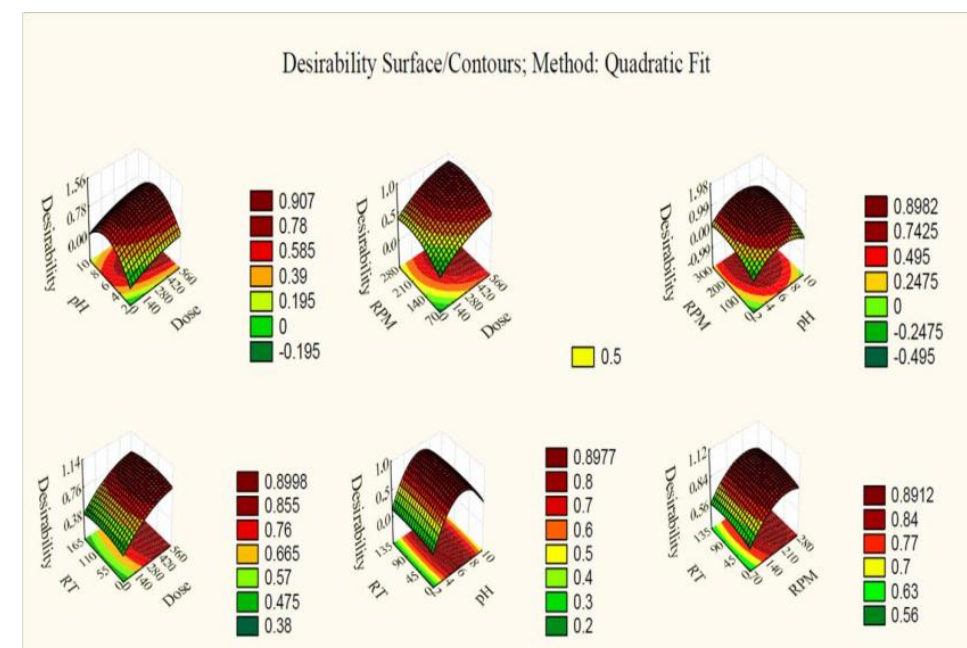

Fig-1: Desirability surface curve for optimized $\mathrm{FeCl}_{3}$ treatment condition at desirability value 0.95 


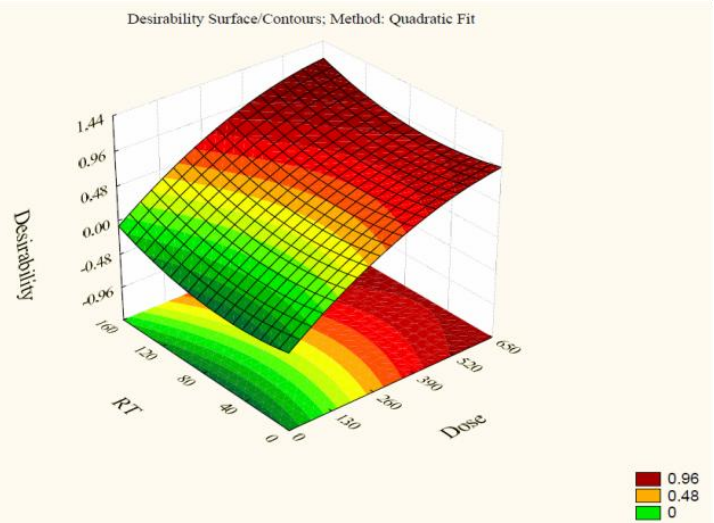

Fig-2: Desirability surface curve for optimized activated charcoal treatment condition at desirability value 0.91

\section{Conclusion}

The coagulation and adsorption by using $\mathrm{FeCl}_{3}$ and activated charcoal were investigated in the present study. Since pulp and paper mill effluent having high color and COD, precipitation and adsorption can be effective treatment processes for such effluent. Based on the results obtained it is revealed that the chemicals like ferric chloride and activated charcoal are found effective for treatment of effluent to reduce COD, BOD, color and AOX which are one of the main environmental regulatory parameters. The iron salt was able to precipitate color as well as COD and BOD from the wastewater. The precipitation was found to be highly dependent of both $\mathrm{pH}$ and dose of iron salt. The precipitation of pollutants was effective in the $\mathrm{pH}$ range of 4.06.0. Activated charcoal was also found effective to reduce color, BOD and COD respectively at $\mathrm{pH}$ 7.0. Use of these chemicals as pretreatment steps not only reduce the pollution loads, but will also help paper mills in reducing the operating cost of subsequent activated sludge process widely used for treatment of effluent to meet the discharge standards.

\section{Acknowledgements}

The author acknowledge to the Cellulose and Paper Division, FRI, Dehradun and Environment Management Division, Central Pulp and Paper Research Institute, Saharanpur for their help and infrastructure. The author also acknowledge to industry persons for extending their cooperation for providing wastewater samples, whenever required and the generous hospitality offered to us upon each visit.

\section{References}

[1]. K. S. Gayathri and R. Viji. Removal of colour from paper mill waste water using neem leaf powder, International Journal of Applied Engineering Research, 11 (3), 2016, 7-13.

[2]. H. D. Kulkarni. Pulp and Paper Industry Raw Material Scenario-ITC Plantation A Case Study, Indian Pulp and Paper Technical Association, 25, 2013, 79-90.

[3]. D. Pokhrel and T. Viraraghavan. Treatment of pulp and paper mill wastewater -a review, Science of the Total Environment, 333(13), 2004, 37-58.

[4]. V.P. Kesalkar, I. P. Khedikar and A. M. Sudame. Physico-chemical characteristics of wastewater from Paper Industry, International Journal of Engineering Research, 2, 2012, 137-143.

[5]. D. N. Linthoingambi, I. Yadav, S. Singh and S. Belagali. Physicochemical characteristics of paper industry effluents: a case study of South India Paper Mill (SIPM), Environment Monitoring Assessment, 177, 2011, 23-33.

[6]. F. B. Deilek and S. Bese. Treatment of pulping effluents using alum and clay-color removal and sludge characteristics, Water Sanitation, 2(3), 2001, 361-366.

[7]. R. J. Stephenson and S. J. B. Duff. Coagulation and precipitation of mechanical pulping effluents-I. Removal of carbon, color and turbidity, Water Research, 30(4), 1996, 781-792.

[8]. F. Hanafi, O. Assobhei and M. Mountadar. Detoxification and discoloration of Moroccan olive mill wastewater by electrocoagulation, Journal of Hazardous Materials, 174(3), 2010, 807-812.

[9]. M. Y. Ghaly, T. S. Jamil, I. E. El-Seey, E. R. Souaya and R. A. Nasr. Treatment of highly polluted paper mill wastewater by solar photocatalytic oxidation with synthesized nano $\mathrm{TiO}_{2}$, Chemical Engineering Journal, 168(1), 2011, 446-454.

[10]. N. K. Swamy, P. Singh and I.P. Sarethy. Precipitation Of Phenols From Paper Industry Wastewater Using Ferric Chloride. Rasayan Journal of Chemistry, 4, 2011, 452-456.

[11]. N. K. Swamy, P. Singh and I. P. Sarethy. Color and phenols removal from paper mill effluent by sequential treatment using ferric chloride and Pseudomonas putida, International Journal of Pharma and Bio Sciences, 3(2), 2012, 380-392.

[12]. APHA -AWWA-WPCF. Standard Methods for Examination of Water and Wastewater, 21st edition. American Public Health Association, Washington, DC, USA, 2005.

[13]. Canadian Pulp and Paper Association (CPPA). Technical Section Standard Test Methods. H5. Montreal, 1993, 20-23.

[14]. P. Tripathi, V. Kumar, G. Joshi, S. P. Singh, S. Panwar, S. Naithani and R. Nautiyal. A Comparative Study on Physico-Chemical Properties of Pulp and Paper Mill Effluent, International Journal of Engineering Research and Application, 3(6), 2013, 811-818.

[15]. B. R. Yadav and A. Garg. Treatment of pulp and paper mill effluent using physico-chemical processes, Indian Pulp and Paper Technical Association Journal, 23(2), 2011, 155-160. 